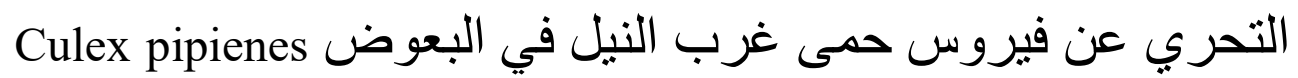 في محافظة حلب باستخدام التقانات المناعية
}

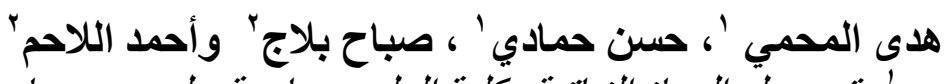

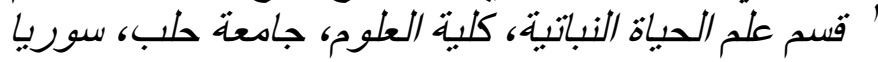

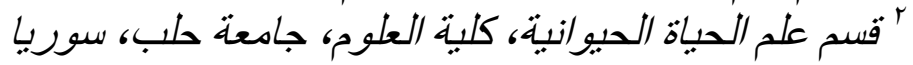

hudamahme@hotmail.com

\begin{abstract}
المستخلص هدف هذا البحث إلى تحديد وجود فيروس غرب النيل في البعوض Culex pipienens في مدينة حلب، ينتسي

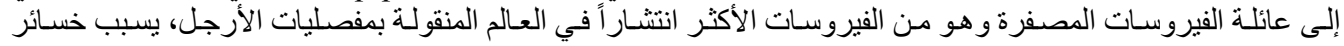

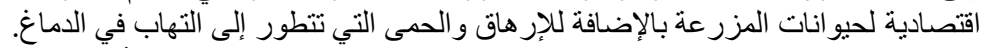

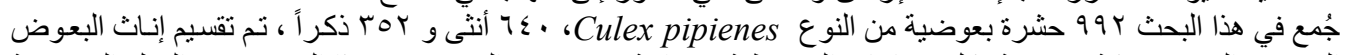

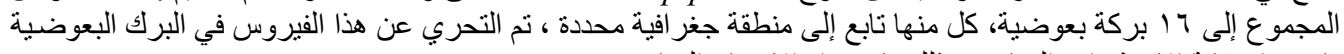

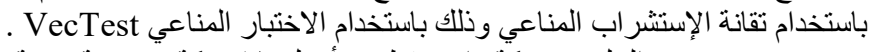

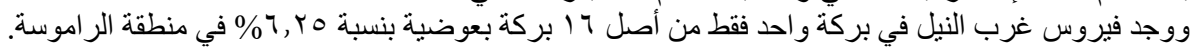

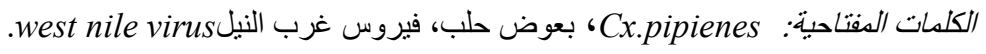

\section{المقدمة مازة}

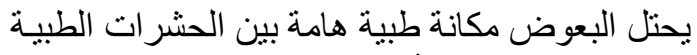

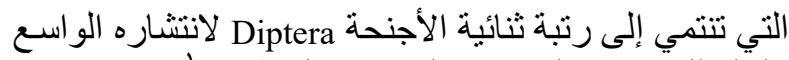

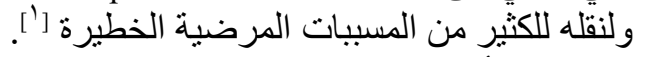

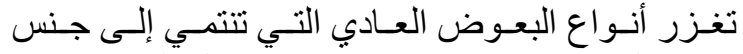

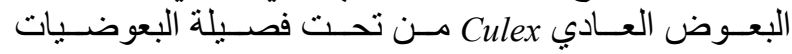
(Culicinae)

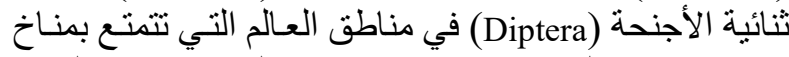

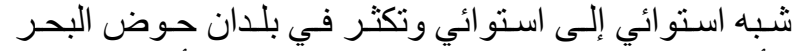

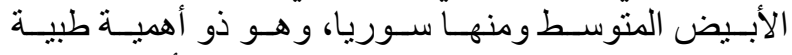

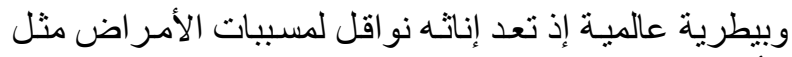

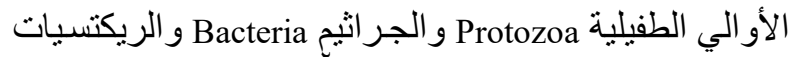
Rickettsiae

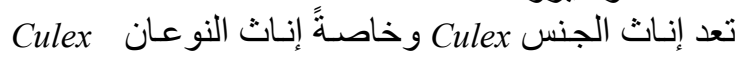

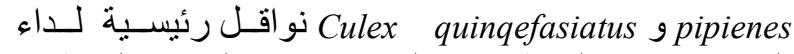

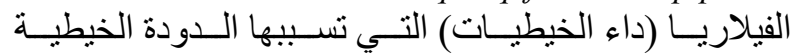
Wuchereria bancrofti

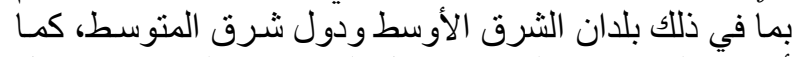

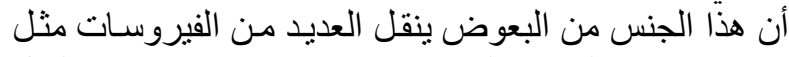

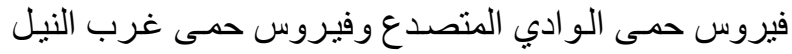

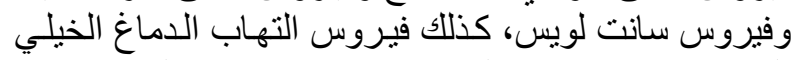

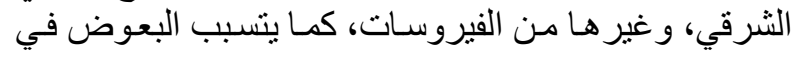

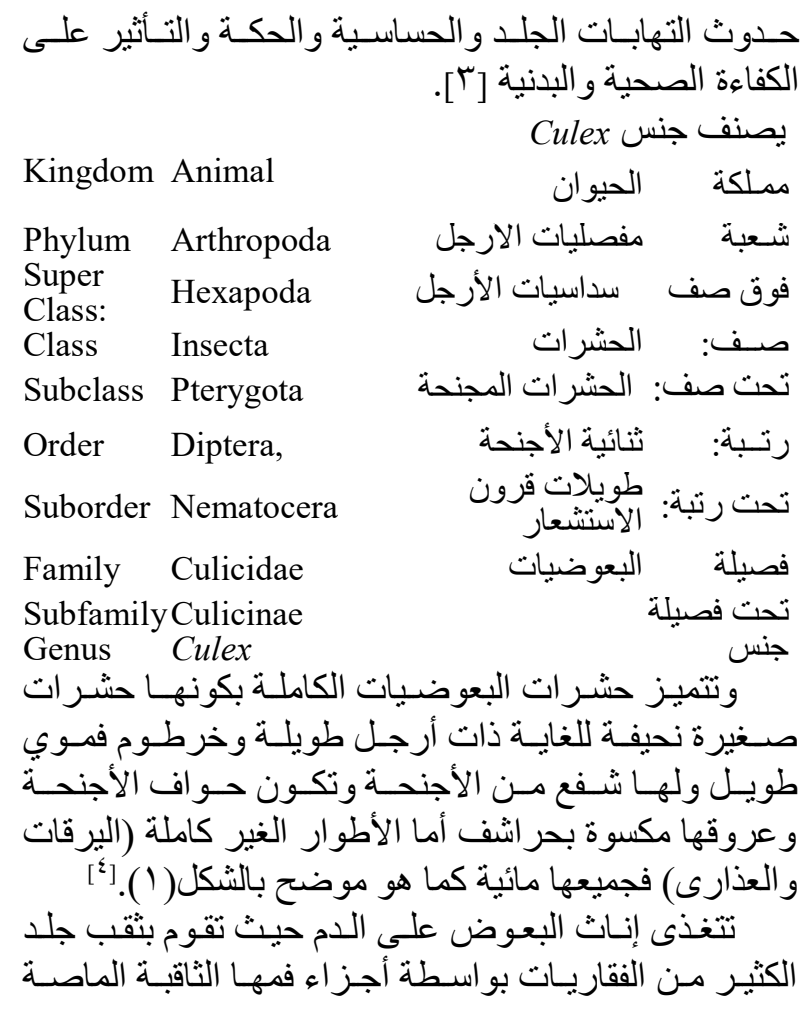


وامتصـاص الـدم نظـر الحاجتهـا للبـروتين مـن أجلـ وضـع

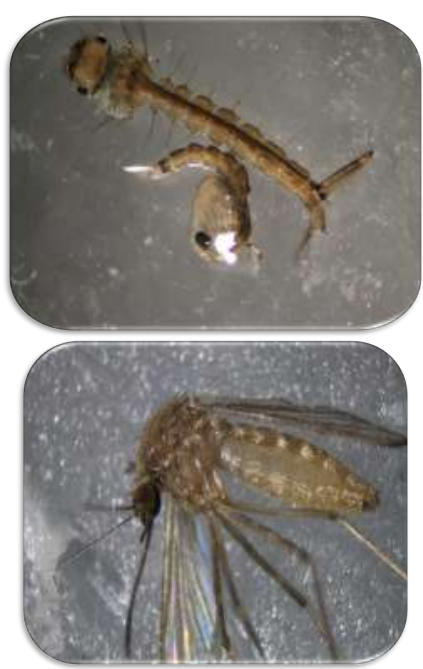

الثكل رقم ( ) الطور البالغ للبعوض والأطوار غير الكاملة

فيروس حمى غرب النيل West nile virus:

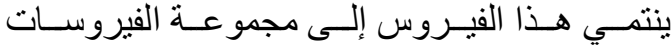

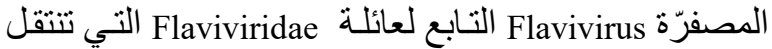
بوساطة مفصليات الأرجل، وتضم مجمو عة من الفيروسـات التهات

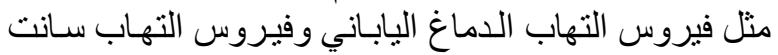
لويس وفيروس التهاب الدماغ الخيلّي الثرقي.

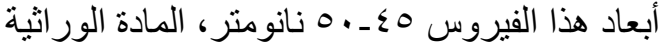

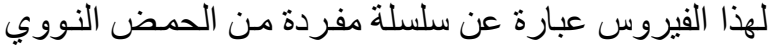

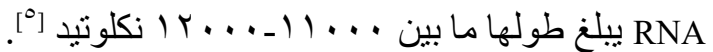

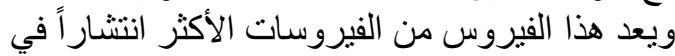

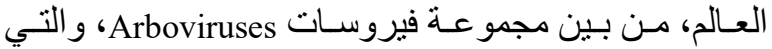
تؤثر في مجمو عة و اسعة من الفقاريات بما في ذلك الطيور

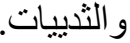

تنطوي الدورة الطبيعية لهذا الفيروس على الطيور

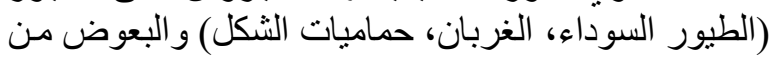

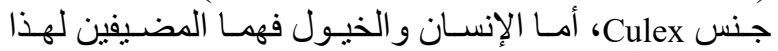

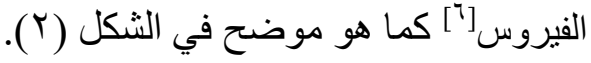

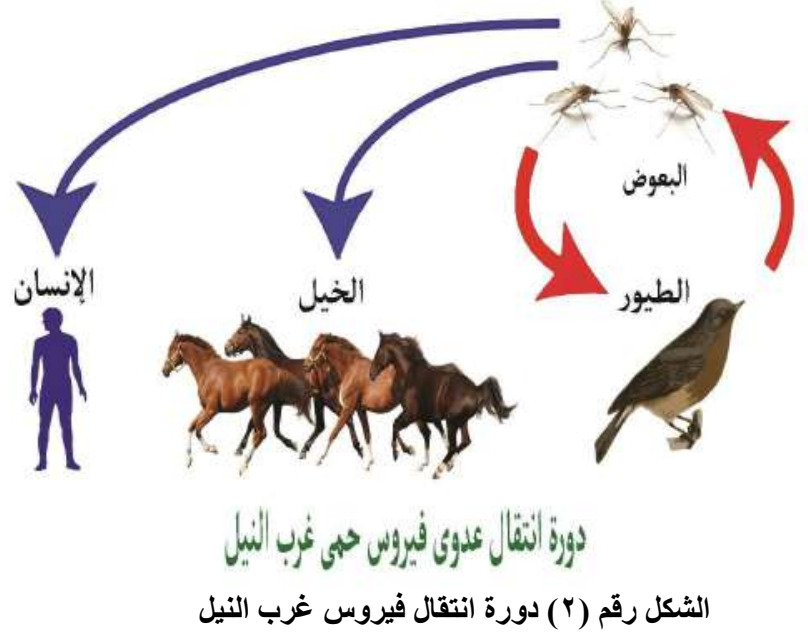

تعتبر الطيور المصاب الأول بالفيروس، يتم تكاثر الفيروس

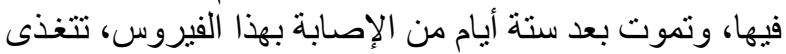

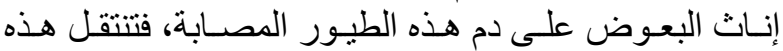

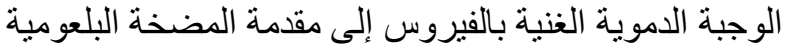

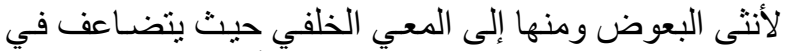

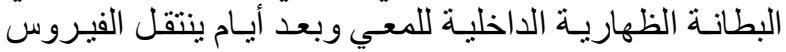

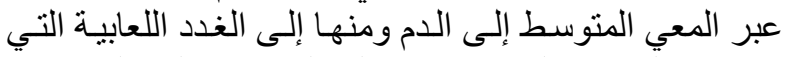

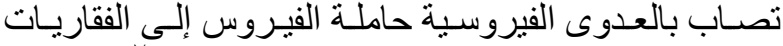

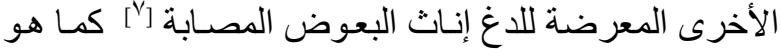

موضح في الشكل(r).

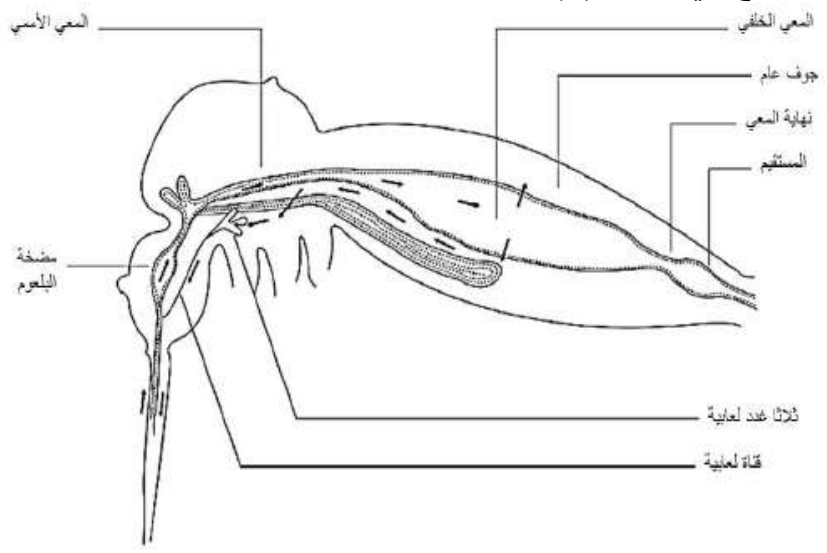

$$
\text { الثكل رقم ("اّ) مسار الفيروس داخل الحشرة }
$$

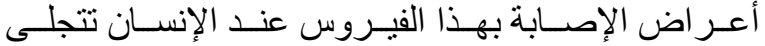

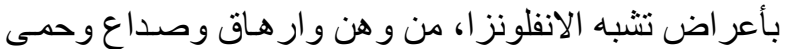

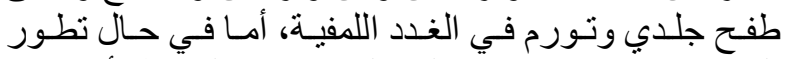

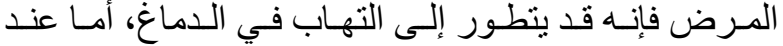

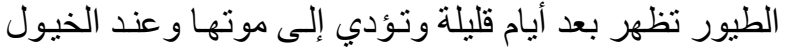

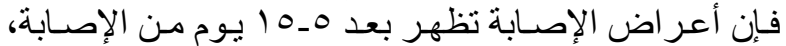

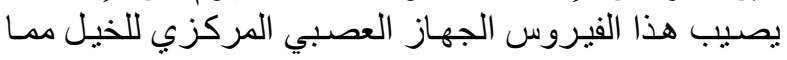


يؤدي إلى التهاب الدماغ و التهاب الأغشية السـحائية، مبــ \% ov من الخيل المصابة تنفق.

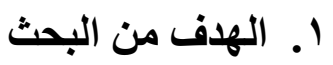

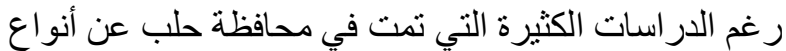

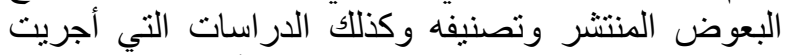

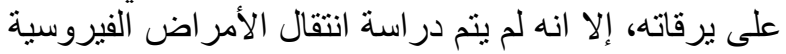

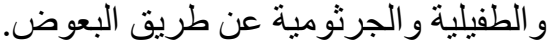

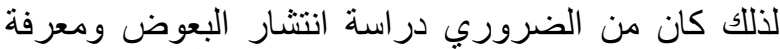

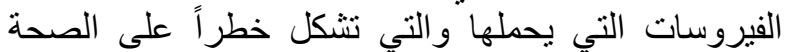

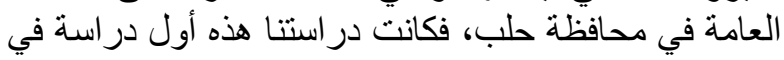

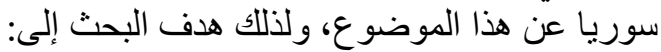
1 ا- - حصر البعوض Culex pipienes في مدينة حلب.

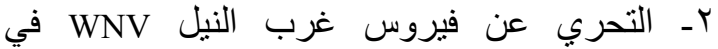
البعوض باستخدام التقانات المناعية.

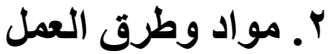

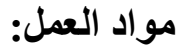

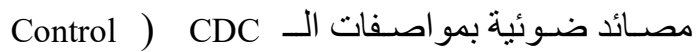
(Disease Center

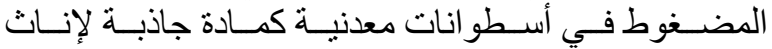

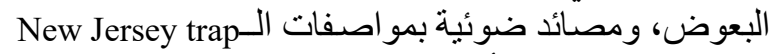
صُمدت في مختبـر أبحـاث الطفيليـات و المناعـة في كليـة العلوم -جامعة حلب.

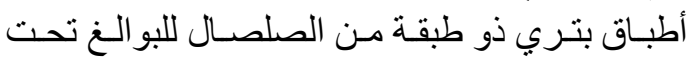

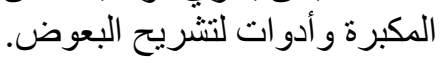

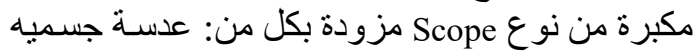

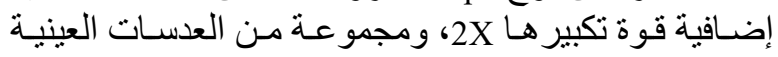

ذات قوى تكبير مختلفة و إضـاءة هالو جينية باردة إضافية. - مواقع جمع العينات:

جمعت العينات البعوضية من موات اقع اقع مختلفة في مدينـة

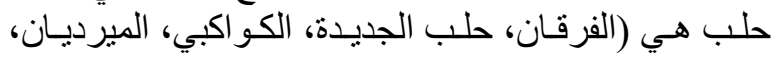

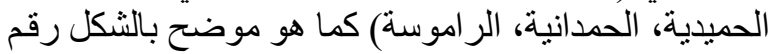

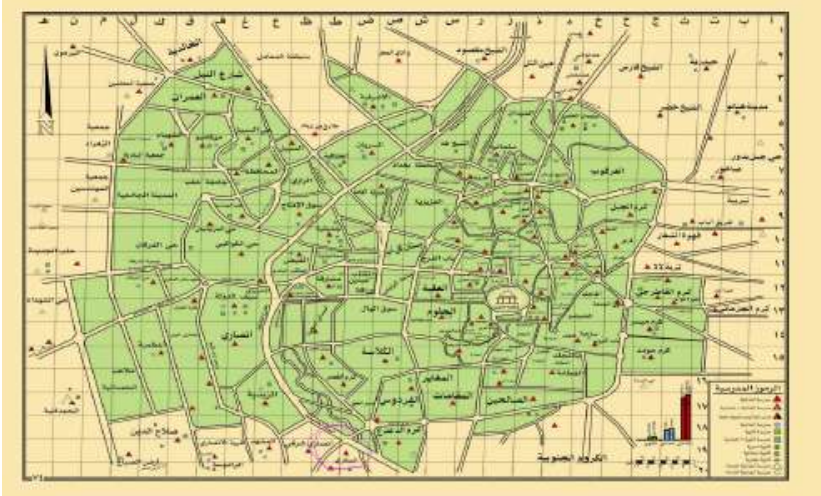

الثكل رقم (؛) خارطة حلب.

جمع حشرات البعوض من البعارطة البيئة الهوائية:

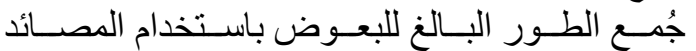

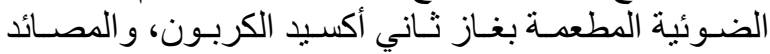

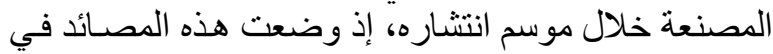

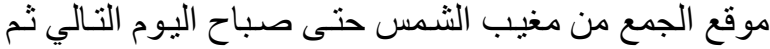

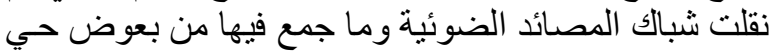

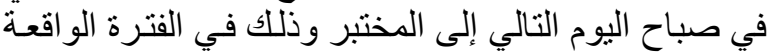

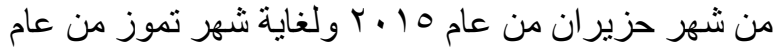
r. 17

\section{- تعريف البعوض مخبرياً:}

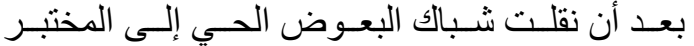
عُوملت تللك الحشر ات وفت مقات ما يلي:

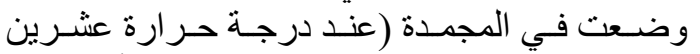

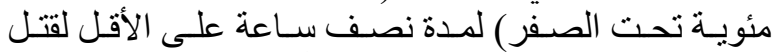
الحشر ات المجمو عة بالتجميد حرصاً على أن تبقى العينـات الأل جافة.

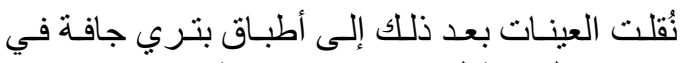

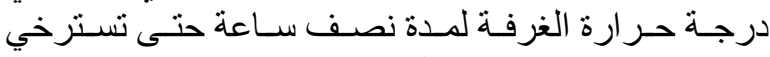
عضلاتها، وصُنفت تحت المكبرة باستخدام مفاتيح تصنيفية

عالمية كما هو موضح بالثكل(0).

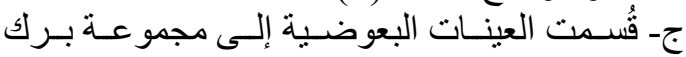

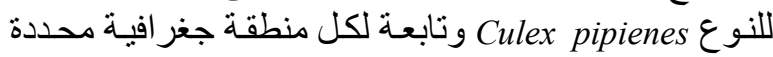
للتحري عن فيروس حمى غرب النيل فيل باستخدام الاختبـار السريع Vec Test. 


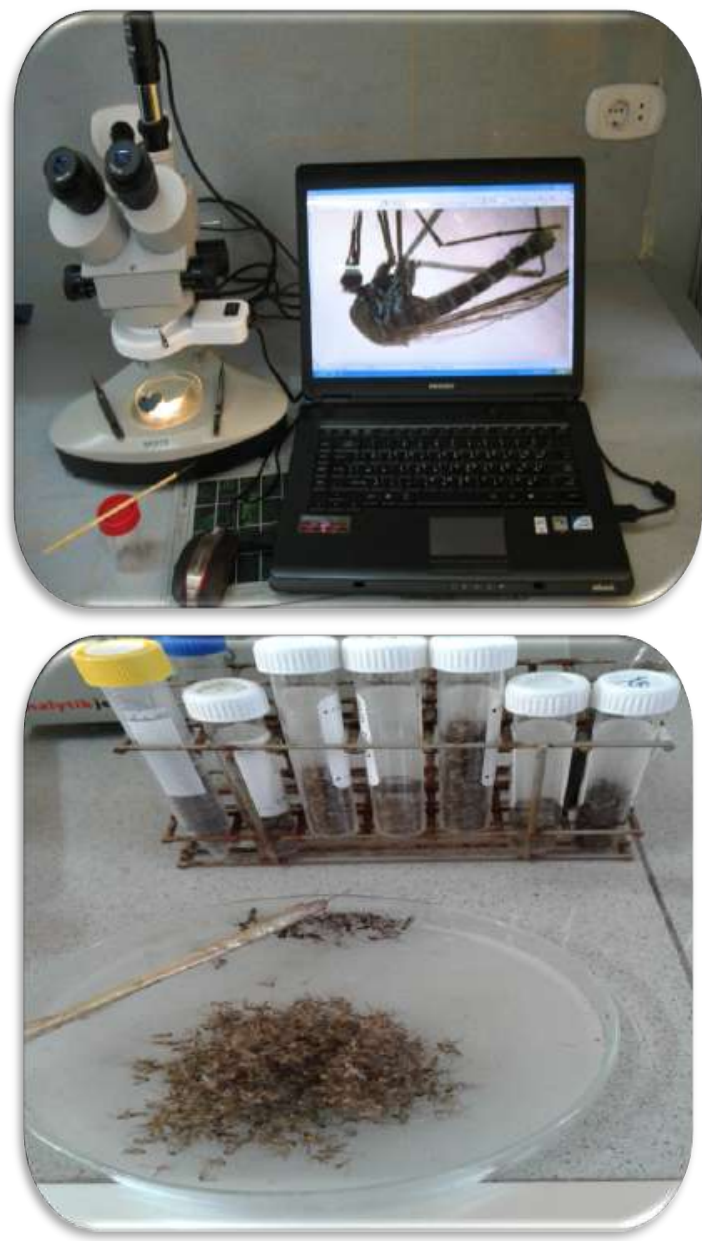

الشكل رقم (•) تصنيف العينات البعوضية وتقسيمها إلى برك

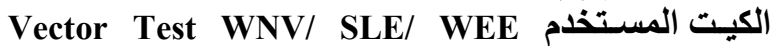

Antigen:

يتكون هذا الكيت من • م- شريط اختبار ، بالإضـافة

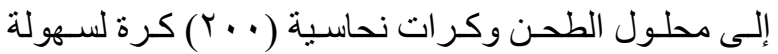

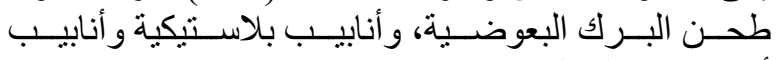

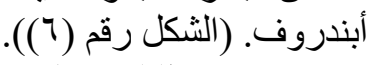

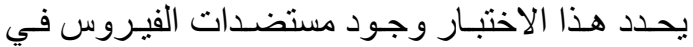

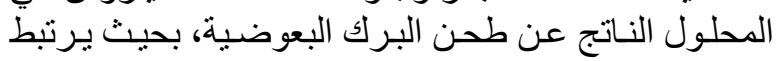

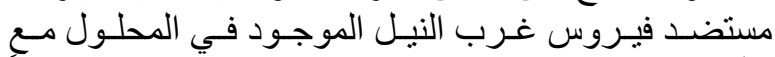

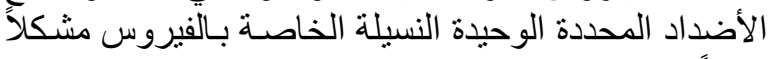

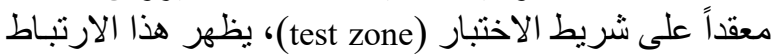
على شكل خط إيجابي بلون أحمر إلى أرجو اني على شريط

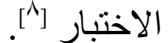
هذا الاختبار من الاختبـار ات المناعيـة السريعة التي تكثف عن مستضدات الفيروس في حال تو اجدها.

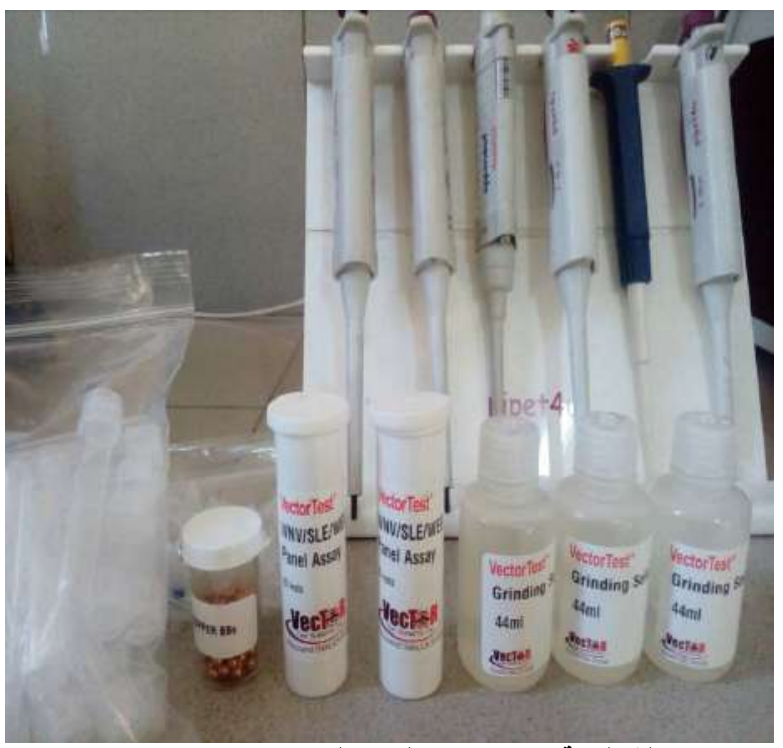

الشكل رقم (") ): مواد الكيت المناعي Vec Test

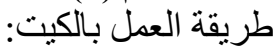
بعد تصنيف العينات البعوضية وفق المفاتيح العالميـة

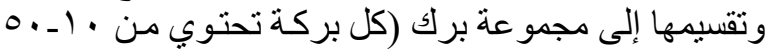

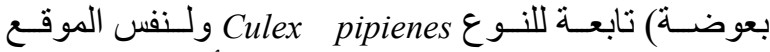

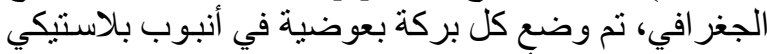

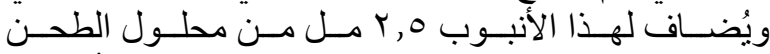
Grinding solution (GS)

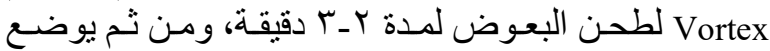

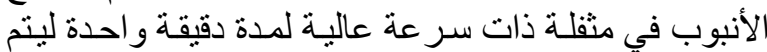

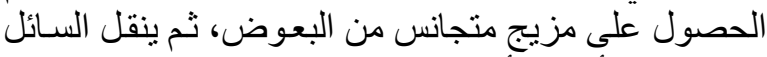

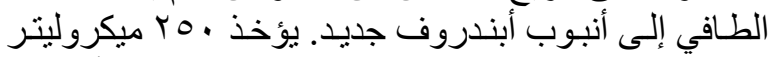

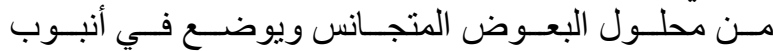

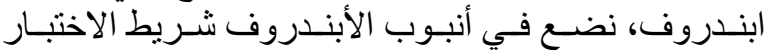

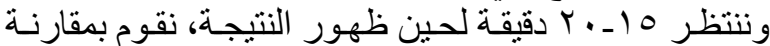
النتيجة مع شريط النتائج المقدم في الكيت كمـا هو موضـح 


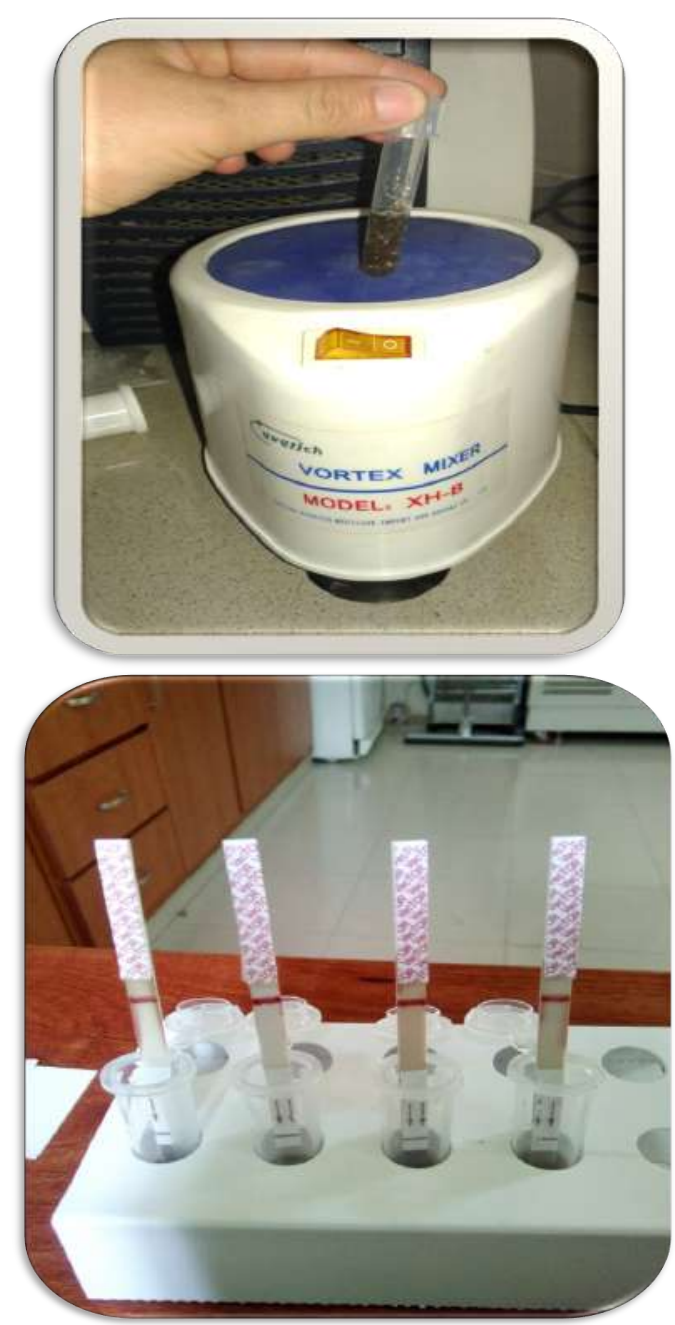

الشكل رقم (V) الشريقة عمل بالكيت المناعي VecTest

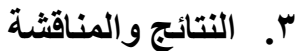

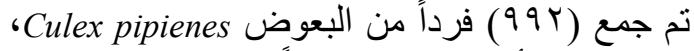

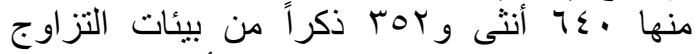

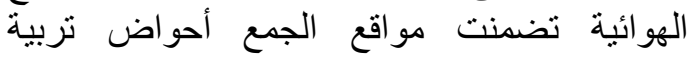

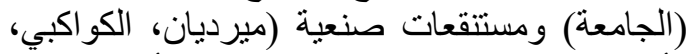

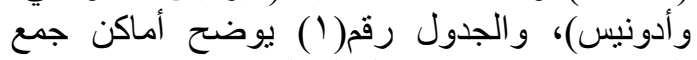
العينات و عددها، و عدد البرك البعان البعوضية.

\begin{tabular}{|c|c|c|c|c|}
\hline \multicolumn{2}{|c|}{ بوالغ } & \multirow[b]{2}{*}{ ذكور } & \multirow[b]{2}{*}{ اناث } & \multirow[b]{2}{*}{ مكان الجمع } \\
\hline عدد البرك & مجموع & & & \\
\hline$\varepsilon$ & $17 \varepsilon$ & 。 & 109 & الر اموسة \\
\hline 1 & TV & rA & $r q$ & الكو اكبي \\
\hline 1 & 4 & 11 & $\infty 0$ & الميرديان \\
\hline
\end{tabular}

\begin{tabular}{|c|c|c|c|c|}
\hline 1 & $\varepsilon v$ & $\wedge$ & $r q$ & 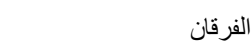 \\
\hline 1 & $r \varepsilon$ & 1 & rᄉ & 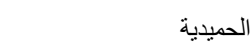 \\
\hline$\varepsilon$ & $\varepsilon . q$ & $r \varepsilon$. & 179 & أققيية الجامعة \\
\hline 1 & r & $r$ & rA & الحمدانية \\
\hline 1 & in & 11 & or & حلب الجديدة \\
\hline 1 & 09 & rr & rv & البيت الأخضر (كلية العلوم) \\
\hline 1 & $\varepsilon v$ & $\wedge$ & rq & البيت الحيواني (كلية العلوم) \\
\hline 17 & १९५ & ror & $T \varepsilon$. & المجمو ع الم \\
\hline
\end{tabular}
pipienes

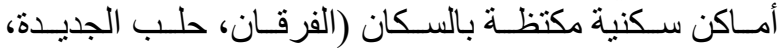

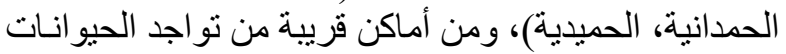

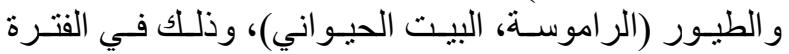

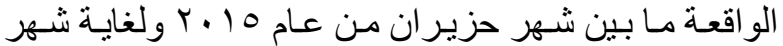

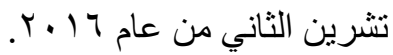

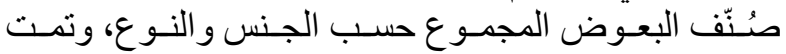

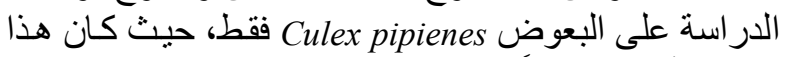

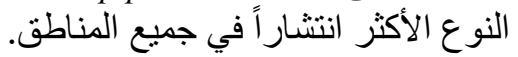

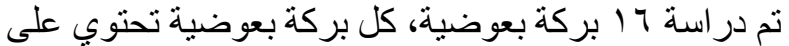

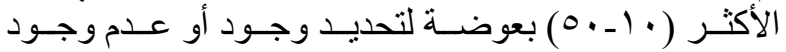

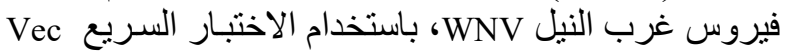

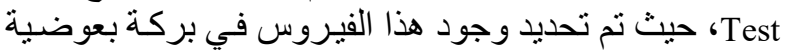

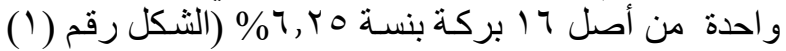

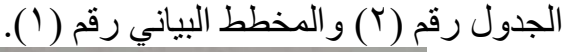

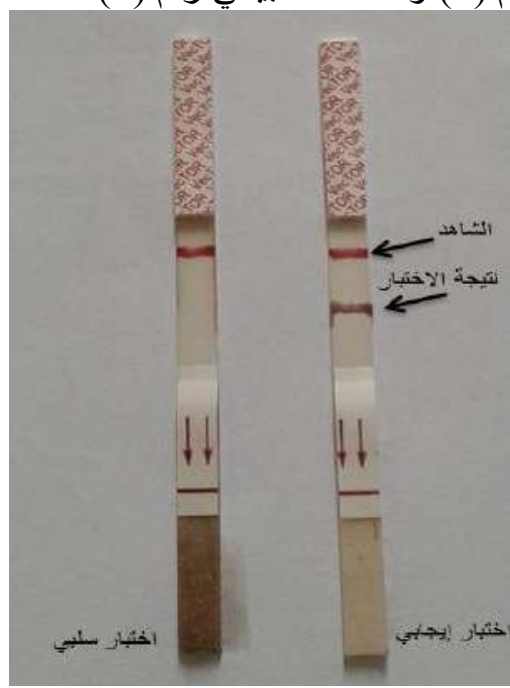

الثكل رقم (') نتيجة الاختبار السريع Vec Test للتحري عن

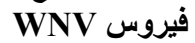

الجدول رقم (Y): عدد بـرك الحشـرات المجـرى عليـه الاختبـار ونسبة 


\begin{tabular}{|c|c|c|c|c|}
\hline للبركبة السلبية & للبرك الإيجابية النئية & موع & البلبية & عدد البيركية \\
\hline $93.75 \%$ & $6.25 \%$ & 16 & 15 & 1 \\
\hline
\end{tabular}

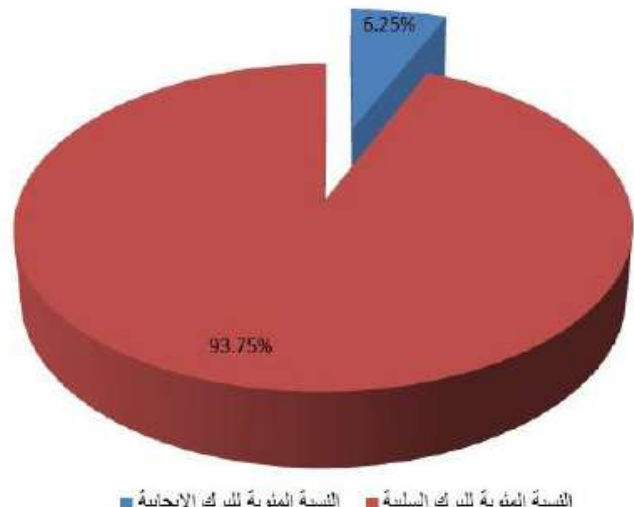

المخطط البياني رقم ( 1 ) نسبة برك الحشرات إيجابية فيروس غرب

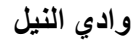

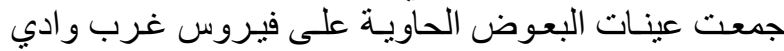

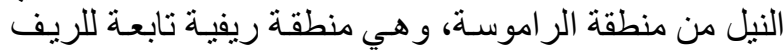

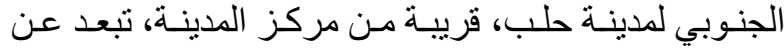

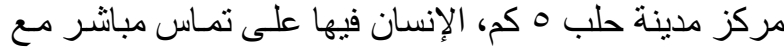

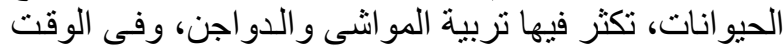

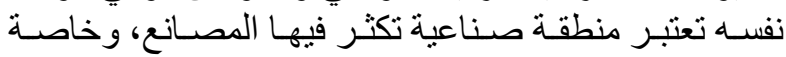

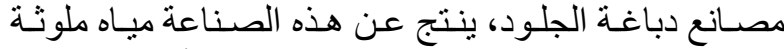

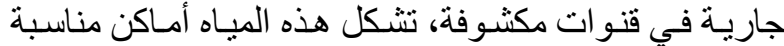

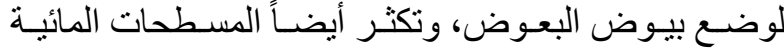

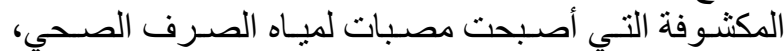

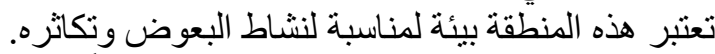

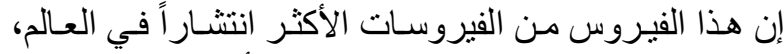

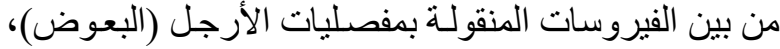
قد انتشر في معظم بلدان العالم.

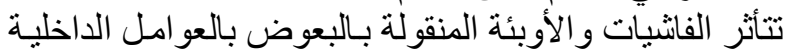

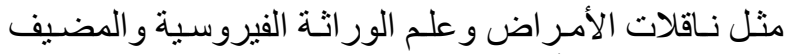

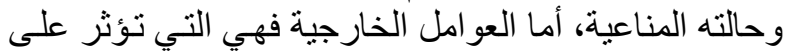

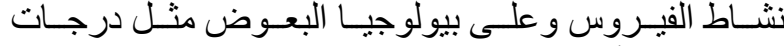

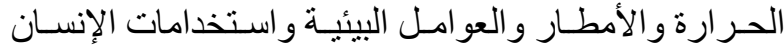

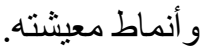

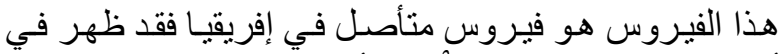

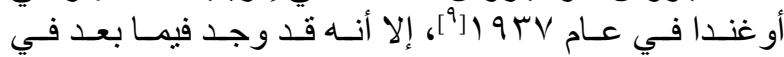

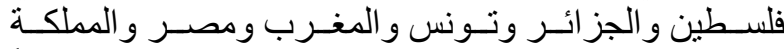

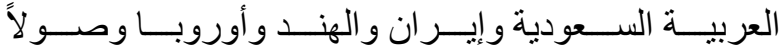

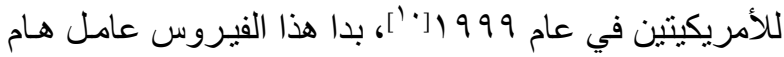

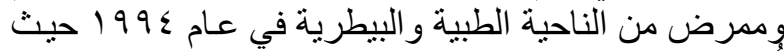
أبلغ في ذلك العام عن حالات تفثي حسادة لهذا الفيروس في في
الطيور و الخيول في الجزائر و المغرب الذي أدى إلى نفوق

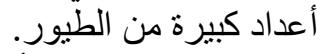

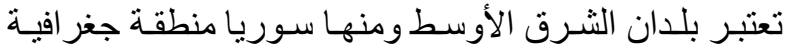

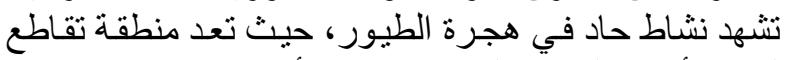

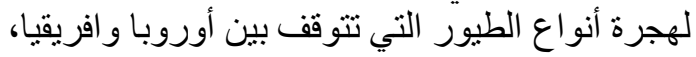

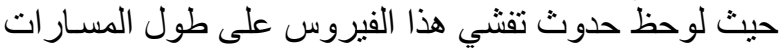
الرئيسية التي تسلكها الطيور المهاجرة. وتتميز سوريا بموقع جغر افي استر اتيجي مهم، بحيث النئ أنها

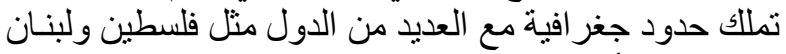

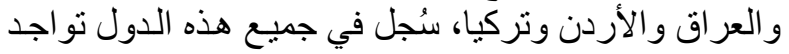

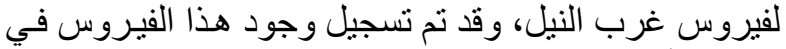
سوريا لأول مرة في بحثنا هذا. تشهد سوريا هجرة كبيرة للطيور في في أثهر الهجرة، قد فيل يلعب

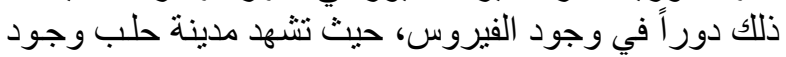

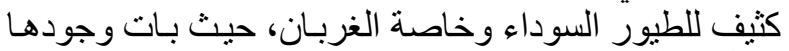

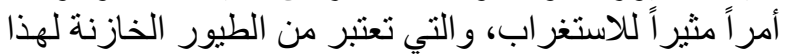

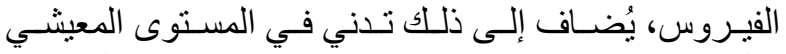

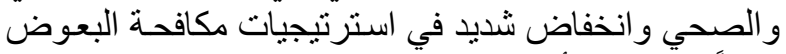

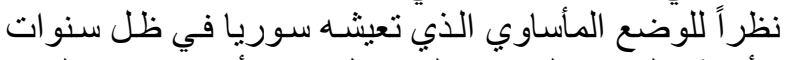

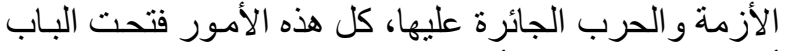

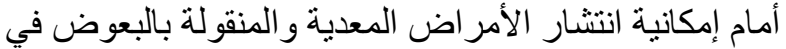

مدينة حلب.

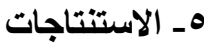

1. سُجل في هذا البحث وجود فيروس غرب و الادي النيل

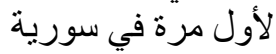

r Culex pipienes حملت إناث البعوض العادي العادي فيروس غرب و الني ادي النيل

r. انتشر فيروس غرب غروب وادي النيل في منطقة الريف نظر اً لتوفر العو ائل الخازنة والناقلة فيها 7. التوصيات

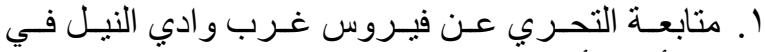

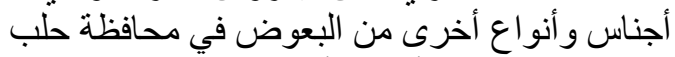

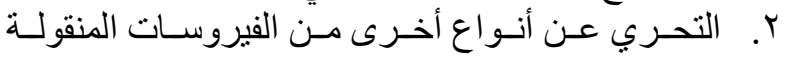

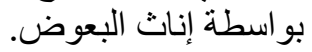

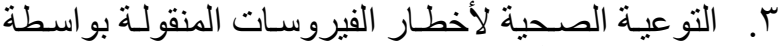
البعوض نظر اً لما تسبيه من أضر ار صحية و اقتصادية.

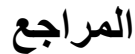

[1] Kumar P.; Murugan K. and Kovendan K., Mosquito larvicidal and pupicidal efficacy of Solanum xanthocarpum (Family : Solanaceae) leaf extract and bacterial insecticide, Bacillus thuringiensis, against Culex quinquefasciatus Say (Diptera : Culicidae). Parasitol Res, 110: 2541-2550 (2012). 
[2] Vanlalhruaia; Kumar N.and Gurusubramania, G., Bacillus sphaericus in the biological control of mosquito vector complex. Sci Vis., 11: 61-71 (2011).

[3] Omar MS. A survey of bancroftian filariasis among South East Asian expatriate workers in Saudi Arabia. Trop Med. Int Health, 1:155-60 (1996)

[4] Harbach, R. E.; Dahl,C.and White, G. B, Culex (Culex) pipiens Linnaeus (Diptera: Culicidae) Concepts, Type Designations, and Description. Proc. Entomol. Soc. WASH. 87: 1-24 (1985)

[5] Fonseca K, Prince G.D, and Bratvold J, West Nile virus infection and conjunctival exposure. Emerging Infect. Dis, 11: 1648-9 (2005).

[6] Hayes EB, Komar N, Nasci RS, Montgomery SP, O'Leary D.R, and Campbell G.L. "Epidemiology and transmission dynamics of West Nile virus disease". Emerging Infect. Dis, 11: 1167-73 (2005)
Clements, A.N, The biology of mosquitoes. Volume 3: Transmission of viruses and interactions with bacteria.. Chapman \& Hall, London . (2012).

[8] Nasci RS, Gotifried KL, Burkhaalyer KL, and Ryan JR, Sensitivity of the Vec Test antigen assay for eastern equine encephalitis and western equine encephalitis viruses.Jm Mosq control AsSoc.Dec. 19: 440-444 (2003).

[9] Smithburn K.C., Hughes, T. P., Burke, A.W, and Paul, J. H. A neurotropic virus isolated from the blood of a native of Uganda. Am. J. Trop. Med.; 20: 471-492 (1940).

[10] Anderson JF, Andreadis TG, Vossbrinck CR, Tirrell S, Wakem EM, and French RA, Isolation of West Nile virus from mosquitoes, crows, and a Cooper's Hawk in Connecticut. Science 286:2331-3.

(1999) 
التحري عن فيروس حمى غرب النيل في البعوض Culex pipienes في محافظة حلب باستخدام الثقانات المناعية

\title{
Detection of West Nile Virus in mosquito Culex pipienes in Aleppo city using Immunological Techniques
}

\author{
${ }^{1}$ Huda Almehmi, ${ }^{1}$ Hasan Hamadi, ${ }^{2}$ Sabah Belaj, ${ }^{2}$ Ahmed Al-lahem \\ ${ }^{1}$ Department. of Plant Biology, Faculty of Sciences, University \\ of Aleppo, Syria \\ ${ }^{2}$ Department. of Animal Biology, Faculty of Sciences, University \\ of Aleppo, Syria
}

ABSTRACT . The aim of this research was to determine the presence of West Nile Virus (WNV) in Culex pipienes in Aleppo city.West Nile Virus (WNV; flavivirus; flaviviridae) is the factor of the most wide spread arthropoda-borne viral disease in the world, WNV causes economic losses to farm animals, as well as fatigue and fever that may develop into encephalitis. In this research (992) Culex pipienes were collected, (640) females and (352) males. The female of Culex pipienes were divided into 16 pools of mosquito each one follow to a specific geographical area. The virus has been investigated in mosquitoes pools using Vec Test antigen capture, West Nile Virus were found in only pool in AlRamousa area in the rate of $6.25 \%$.

Key words: Culex pipiens, West Nile Virus, Vec Test. 